\title{
PIBID E FORMAÇÃO DOCENTE: EXPERIÊNCIA E REFLEXÃO
}

\author{
Amélia Lopez ${ }^{1}$ \\ SEE - Niterói \\ Denise Brasil A. Aguiar ${ }^{2}$ \\ UFF \\ Michelle Aidê ${ }^{3}$ \\ SEE - Niterói
}

\section{RESUMO:}

O texto parte de uma descrição e avaliação do trabalho desenvolvido por meio do Programa Institucional de Bolsas de Iniciação à Docência (PIBID), da CAPES, em escolas da rede pública estadual de Niterói (RJ), por iniciativa da Universidade Federal Fluminense. Discute também a formação docente em Língua Portuguesa, tendo em vista tanto questões específicas do ensino da língua materna - incluindo algumas das disposições dos documentos oficiais - quanto elementos da realidade de escolas da rede pública do Rio de Janeiro. Apontam-se também as perspectivas de impacto do programa na construção do necessário diálogo entre Universidade e educação básica.

PalaVRas-Chave: Língua Portuguesa - Ensino - PIBID

\section{ABSTRACT:}

The text begins with a description and evaluation of the work done in public schools of Niterói $(\mathrm{RJ})$, with the initiative of the Fluminense Federal University, supported by Institutional Program of initiation to Teaching (PIBID), CAPES. It also discusses the Portuguese language teacher training, with a view of specific issues of the teaching of mother tongue-, including some of the provisions of the official documents, as elements of public school reality in Rio de Janeiro. It points out the program impact in building of the necessary dialogue between University and basic education.

KEYWORDS: Portuguese Language - Teaching - PIBID

"Tu és a história que narraste, não o simples narrador" ("História, coração, linguagem", de Carlos Drummond de Andrade) 
e-Mosaicos - Revista Multidisciplinar de Ensino, Pesquisa, Extensão e Cultura do Instituto de Aplicação Fernando Rodrigues da Silveira (CAp-UERJ) ANO 1 - V. 1 - N. 2 - DEZEMBRO 2012 - ISSN: 2316-9303

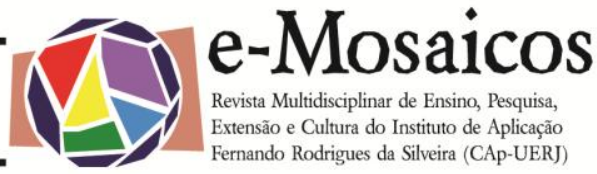

Este é um texto feito a seis mãos, mas esperamos que nele reverbere o trabalho de muitas outras mãos e ecoem os sons de muitas outras vozes. Vozes do fazer docente, da prática cotidiana em sala de aula, daqueles que buscam enfrentar os muitos desafios postos para quem ensina e para quem ensina a ensinar. Estamos falando de uma experiência específica de formação docente, advinda do PIBID (Programa de Bolsas de Iniciação à Docência da Capes), realizado na Universidade Federal Fluminense (UFF), particularmente em sua "edição" 2011, mas acreditamos que o que se discutirá também pode constituir terreno comum para professores e licenciandos partícipes de outras experiências, grupos e espaços.

Oficialmente, o PIBID é descrito como "uma proposta de valorização dos futuros docentes durante seu processo de formação", cujo objetivo é o "aperfeiçoamento da formação de professores para a educação básica e a melhoria de qualidade da educação pública brasileira" (http://capes.gov.br/ educacao-basica/capespibid). O caráter genérico da definição e do objetivo, por si só, trazia alguns receios e já pressupunha um direcionamento a ser dado por aqueles que, efetivamente, iriam e irão fazer a história de um programa dessa natureza, aberto para o Brasil inteiro. Assim, se, por um lado, sempre havia o risco de que todo o trabalho caísse no esvaziamento dos programas sujeitos às intempéries da política de plantão, sem continuidade, ou, pior ainda, que se alinhasse com formas rebaixadas de "treinamento em serviço"; por outro, estava claro também que seria uma oportunidade de intervir, de maneira mais organizada e coletiva, na formação docente voltada para a educação pública e seus desafios.

Como pano de fundo, ainda, a convicção de que a melhoria da escola pública depende também de uma revisão radical da necessidade de investimento na educação, da compreensão da dimensão estratégica de se tornar o magistério uma carreira atraente para talentos que hoje se afastam da sala de aula pelos salários desanimadores. Hoje parece sentimento comum aos profissionais das escolas em que atuamos a ideia de que o fato de a educação pública estar no centro do debate nacional acerca dos principais problemas de nosso país, infelizmente, não tem se traduzido numa melhoria efetiva de sua qualidade. $O$ que se verifica, de fato, são salários desmotivadores, instalações e condições de trabalho precárias, programas educacionais populistas em sua maioria pouco preocupados verdadeiramente com a educação de nossos jovens, entre outros problemas.

Decorrido mais de um ano de nossa participação no programa, cremos que alguns dos receios iniciais foram sendo superados - pela própria expansão do PIBID, que ganhou estabilidade institucional, e pela atuação comprometida do grupo que congrega diversas disciplinas no âmbito do PIBID/UFF, sempre atento à necessidade de combinar a prática docente com a consolidação teórica e crítica na formação dos licenciandos. O contato direto com o cotidiano escolar e com as políticas para a escola pública - estas vistas a partir do microcosmo constituído pelas escolas em que atuamos - trouxe-nos, entretanto, novas preocupações, que procuraremos partilhar um pouco, no contexto também do debate teórico-crítico mais geral sobre o ensino.

\section{O PROJETO INICIAL: METAS E DESAFIOS}

O projeto inicial do PIBID/UFF/Letras, tal como foi apresentado à Capes, em 2011, previa ações em duas frentes - nas escolas e no âmbito acadêmico - que se articulariam na busca da melhoria da qualidade de 
e-Mosaicos - Revista Multidisciplinar de Ensino, Pesquisa, Extensão e Cultura do Instituto de Aplicação Fernando Rodrigues da Silveira (CAp-UERJ)

ANO 1 - V. 1 - N. 2 - DEZEMBRO 2012 - ISSN: 2316-9303

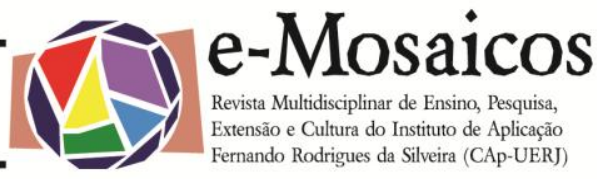

ensino na educação básica. Buscava-se, nas escolas da rede pública de ensino, uma inserção coletiva, qualificada e planejada, que visasse tanto à análise das práticas referentes ao ensino da língua materna desenvolvidas hoje no cotidiano de tais instituições, quanto à formulação de novas alternativas didáticas, com o objetivo de contribuir para a superação de dificuldades, especialmente no desenvolvimento das competências relacionadas à leitura e à escrita. Nas atividades exercidas diretamente junto às escolas da educação básica, propunha-se que os licenciandos em Letras elaborassem projetos de exercício da docência, sob a supervisão e coordenação dos professores da Universidade e das escolas.

$\mathrm{Na}$ implementação do projeto, algumas ações gerais estavam previstas, conforme referido a seguir:

- Discussão de textos integrantes de uma bibliografia básica, de caráter teóricocrítico, além dos documentos oficiais que regem o ensino do português na educação básica, para fundamentar tanto sua compreensão científica sobre os fenômenos da linguagem (particularmente aqueles ligados aos conceitos de texto, discurso, gêneros e variabilidade linguística), quanto sua reflexão acerca do ensino de língua materna;

- levantamento e discussão das principais dificuldades para o cumprimento dos objetivos do ensino do português - tal como preconizados pelos PCNs e largamente referendados pelos estudos da linguagem - nas escolas atendidas pelo subprojeto, como subsídio para a formulação de novas atividades didáticas;

- aplicação dos projetos de ação docente nas escolas;

- avaliação e balanço da aplicação de cada projeto e da implementação, de caráter mais abrangente, do subprojeto, com a participação do maior número possível de envolvidos (coordenadora, supervisores, licenciandos, estudantes das escolas);

- produção de textos e materiais diversos que partilhassem os conhecimentos e experiências acumulados no decorrer da implementação do subprojeto - em suas diversas faces - com a comunidade acadêmica e escolar.

Após um ano de desenvolvimento dos projetos ligados ao Programa, foi possível fazer um balanço parcial, conforme expresso em relatório para a Capes identificando alguns avanços (e outras tanta dificuldades) para a alteração do ensino de língua portuguesa nas escolas. Dentre os elementos parciais de balanço, destaquem-se:

- No âmbito da formação universitária: um conhecimento mais aprofundado acerca de documentos oficiais relativos ao ensino de Língua Portuguesa, que norteiam o ensino da disciplina na educação básica, principalmente para os licenciandos; a reflexão mais aprofundada acerca das novas exigências da profissão docente, das especificidades do ensino de língua materna, especialmente no que diz respeito ao desenvolvimento de habilidades de leitura e escrita com estudantes da educação básica; a consolidação de base teórico-crítica para a formulação de projetos e produção de trabalhos de acadêmicos; o incentivo à construção de uma autonomia pedagógica, pela progressiva conquista de requisitos para a composição de materiais próprios (seleção de estratégias, de textos, elaboração de propostas de atividades etc).

- No âmbito da formação e da prática nas escolas. uma inserção mais qualificada no cotidiano das escolas; um exercício de construção de ações docentes voltadas para 0 atendimento aos preceitos 
e-Mosaicos - Revista Multidisciplinar de Ensino, Pesquisa, Extensão e Cultura do Instituto de Aplicação Fernando Rodrigues da Silveira (CAp-UERJ)

ANO 1 - V. 1 - N. 2 - DEZEMBRO 2012 - ISSN: 2316-9303

básicos do ensino de língua materna nas escolas, conforme expectativa contida nos documentos oficiais e acúmulo específico entre os estudiosos da área, no âmbito das Universidades; construção de um convívio regular com os estudantes da educação básica como forma de aprendizado e de estabelecimento de bases mais coletivas para o trabaIho escolar.

- Em uma perspectiva global: iniciação ou ampliação de experiência acadêmica de exposição de trabalho em evento; diálogo com estudantes de licenciaturas e profissionais das diversas disciplinas e áreas; acúmulo de experiências relacionadas ao cotidiano docente, como forma de inserção na realidade das escolas, já como professor em formação; troca de experiências e saberes em diversos níveis; afirmação do caráter coletivo da reflexão e da ação docente na educação básica.

Na primeira etapa, além das leituras e das discussões preparatórias, foram elaborados subprojetos de atuação docente pelos licenciandos, que passaram a produzir atividades que buscavam articular suas propostas aos conteúdos e objetivos estabelecidos junto com os professores supervisores. A sucinta descrição dos projetos dos licenciandos, listados abaixo, ajuda a compreender a etapa do trabalho:

- "A argumentação e suas manifestações nos atos de fala da sociedade", elaborado pelas bolsistas Letícia Vieira da Conceição e Viviane da Silva Faria, com idealização e atividades voltadas para o exercício de um gênero de escrita fundamental para os estudantes, seja para ingresso no ensino superior, seja para a participação cidadã na sociedade.
- $\quad$ "Entre a imagem, a leitura e a produção textual", de autoria das bolsistas Isabela Souza e Amanda Marins, com foco no gênero carta, a partir de estímulo visual, com obra cinematográfica, e desenvolvimento ligado a personagens de livros clássicos da literatura brasileira.

- "O contexto motivacional da produção escrita através da leitura", apresentado pelas bolsistas Giulia Rodrigues, Nathalia Claudino e Raphaele Gama, para desenvolvimento na sala de leitura, com vistas a atividades de leitura, retextualização e criação de textos, a partir da leitura de obra dirigida ao público jovem.

- "Retextualização e reflexão crítica: a leitura e escrita como experiências para além da sala de aula", formulado pelos bolsistas Alaiane de Fátima dos Santos Silva e Álvaro Fernando Motta de Oliveira Filho, com o objetivo de constituir e/ou aprimorar a capacidade de interpretação e produção textual, contribuindo para o desenvolvimento da reflexão crítica sobre os diferentes tipos de texto.

- "Leitura comparativa: construindo um leitor crítico", idealizado pelas bolsistas Cirlene Antunes, Isabela Canossa e Tatiana Goulart, com foco na comparação entre diversos gêneros textuais, a partir de uma motivação temática que perpassa a leitura e a produção de textos.

- Projeto "Paródia: entretenimento e satisfação na produção textual", realizado pelas bolsistas Dayana Gomes Marques e Renata Jesus Porto, com o objetivo de explorar a intertextualidade, em uma perspectiva lúdica, estimulando a escrita e a circulação de textos dos estudantes no espaço escolar.

Por outro lado, as dificuldades encontradas foram, no geral, aquelas previsíveis para 
e-Mosaicos - Revista Multidisciplinar de Ensino, Pesquisa, Extensão e Cultura do Instituto de Aplicação Fernando Rodrigues da Silveira (CAp-UERJ)

ANO 1 - V. 1 - N. 2 - DEZEMBRO 2012 - ISSN: 2316-9303

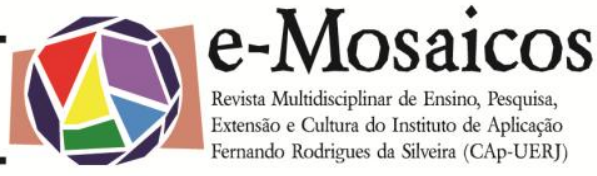

os que conhecem o cotidiano escolar e a formação docente:

- licenciandos a princípio receosos do contato com a escola pública, na condição de professores em formação (para alguns deles se tratava do primeiro contato dessa natureza), o que exigiu leitura e debate de textos acerca das novas exigências da profissão docente hoje e uma inserção cuidadosamente supervisionada deles nas salas de aula;

- esvaziamento das escolas em função da greve dos profissionais da educação na rede pública do Rio de Janeiro, em 2011, o que inicialmente limitou as possibilidades de horários para acompanhamento das turmas, especialmente em uma das escolas;

- instabilidade institucional em uma das escolas, em virtude da rotatividade de direções, fruto da ausência de um modelo estável de gestão democrática na rede, além da flutuação das turmas, em função das políticas de otimização de turmas que a Secretaria de Educação do Estado do Rio de Janeiro realiza a qualquer tempo, fechando e unificando turmas à revelia das necessidades pedagógicas dos estudantes;

- licenciandos com dificuldades consideráveis para a formulação e estruturação de projetos com autonomia, o que foi minimizado por dinâmica de apresentação prévia coletiva e pelo exercício supervisionado da reelaboração e reescritura;

- deficiências gerais de formação inicial dos licenciandos na área de conhecimento e, em alguns casos, até no domínio da variedade padrão da língua, lacunas que o Programa não pode preencher sozinho, mas que buscamos enfrentar pela afirmação da necessidade de estudar previamente os conteúdos a serem expostos e por meio de um a- companhamento, especialmente na produção escrita dos próprios bolsistas.

Como síntese e já antecipando um elemento de avaliação, cremos que, na balança entre intenções e obstáculos, o maior impacto que pode ser percebido em virtude da instauração do PIBID/UFF na área específica de Língua Portuguesa foi o incentivo ao exercício da docência, muito para além das tradicionais aulas de descrição linguísti$\mathrm{ca}$ e normas gramaticais. No curso das atividades do Programa, os bolsistaslicenciandos puderam ler e discutir o que preconizam os documentos oficiais, bem como travar conhecimento com as reflexões de especialistas na área de ensino de língua materna. Apropriando-se de alguns instrumentais teórico-críticos essenciais, desenvolveram projetos de intervenção docente que, como se pode perceber pelo que foi listado anteriormente, demonstram o sucesso dessa orientação geral: todos eles foram elaborados priorizando saberes ligados à leitura e escrita - pontos nevrálgicos do ensino da língua, como indicam as muitas análises e aferições do desempenho dos estudantes da educação básica no Brasil.

\section{PCNS E CuRRículos Mínimos: DOCUMENTOS OFICIAIS E PRÁtICAS ESCOLARES}

Há mais de uma década os Parâmetros Curriculares Nacionais apresentaram uma revisão de muitos aspectos pertinentes à educação básica, dentre eles os que dizem respeito ao ensino de Língua Portuguesa. Especificamente em relação à língua materna, pode-se dizer que foram trazidos à tona debates que há muito vinham sendo feitos pelos círculos acadêmicos de estudiosos da linguagem. Questões como a variabilidade linguística, os gêneros textuais e as práticas sociais, a centralidade do texto nas aulas de 
e-Mosaicos - Revista Multidisciplinar de Ensino, Pesquisa, Extensão e Cultura do Instituto de Aplicação Fernando Rodrigues da Silveira (CAp-UERJ) ANO 1 - V. 1 - N. 2 - DEZEMBRO 2012 - ISSN: 2316-9303

língua portuguesa, o lugar do ensino da norma padrão, entre outros, ganharam o destaque necessário em se tratando de professores de língua portuguesa, especialmente se pensarmos na ênfase descritivonormativa que dominava o ensino do português à época da formulação e divulgação dos PCNs.

Embora não se possa deixar de apontar que iniciativas oficiais não produzem efeitos substanciais, amplos e duradouros, se não vierem acompanhadas de uma política real de valorização do trabalho do professor, é possível afirmar, com alguma tranquilidade, que, pelo menos do ponto de vista teórico, os PCNs trouxeram mais acertos do que equívocos. No rumo da transformação de práticas e crenças que têm se demonstrado de pouca eficácia na contemporaneidade, configura-se, de fato, como sendo de grande relevância a sinalização explícita da centralidade do texto nas aulas de língua portuguesa - em substituição à histórica tendência de descrição e prescrição a partir de corpus irreal ou de frases descontextualizadas -, a ênfase na exploração didática dos gêneros textuais, a busca de configuração de novos conteúdos ligados às praticas sociais (inclusive nos domínios da oralidade).

É claro que tais documentos, ainda que inscritos em terreno de relativo acordo entre especialistas da área, não se construíram sem o signo da discordância e, por vezes, da contradição. Em seu artigo "PCNs, gêneros e ensino da língua: faces discursivas da textualidade", Beth Brait (2000) já aponta o que ela considera uma mescla indiscriminada dos conceitos de gênero e tipo textual, na extensa explanação dos PCNs de Língua Portuguesa, além do problema, mais grave do ponto de vista teórico, de que a cristalização de conteúdos relativos aos gêneros seria contrária ao espírito das formulações bakhtiniana:
Sem qualquer pretensão de querer fechar Bakhtin em uma única leitu$\mathrm{ra}$, o que seria incoerente com sua concepção dialógica da linguagem, as indicações dos PCNs podem ser coerentes, e de fato o são em vários aspectos, mas, encerrando o trabalho com o texto em modelos preestabelecidos, afastam-se da proposta do dialogismo bakhtiniano diante do texto, dos discursos, da vida, do conhecimento. Ainda que as teorias escolhidas para o ensino e a aprendizagem tenham como fonte, entre outras, o pensamento bakhtiniano, a restrição impede um trabalho mais aberto e histórico com os textos e com seus leitores. (BRAITH, 2000, p.24)

Não obstante essas ressalvas, feitas já por ocasião do lançamento dos PCNs, é possível constatar que, passada mais de uma década de sua divulgação, as disposições relativas ao ensino de língua materna conseguiram consolidar algumas referências importantes. Sobretudo se pensarmos nos livros didáticos (bem adaptados, como todo produto comercial de sucesso, às novas exigências do "mercado", particularmente à seleção promovida pelo MEC através do PNLD), no perfil de provas de seleção de professores e estudantes em diversas instituições no país e também em alguns desdobramentos, também oficiais, no âmbito de alguns estados e municípios.

Particularmente no Estado do Rio de Janeiro, os Parâmetros encontram um desdobramento concreto na elaboração dos "Currículos Mínimos" (disponíveis em http://www.rj.gov.br/web/seeduc), a serem aplicados ao conjunto da rede, declaradamente inspiradas nos PCNs. Com as dificuldades que toda iniciativa homogeneizadora dessa natureza já carrega e ainda com problemas advindos inicialmente de uma for- 
e-Mosaicos - Revista Multidisciplinar de Ensino, Pesquisa, Extensão e Cultura do Instituto de Aplicação Fernando Rodrigues da Silveira (CAp-UERJ)

ANO 1 - V. 1 - N. 2 - DEZEMBRO 2012 - ISSN: 2316-9303

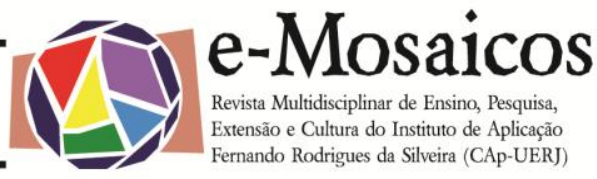

mulação inicialmente açodada, os conteúdos foram levados obrigatoriamente para todas as escolas, sob a batuta da cobrança em exame próprio e centralizado da rede no SAERJ - Sistema de Avaliação da Educação no Estado do Rio de Janeiro. A aplicação dos Currículos Mínimos, para dizer o mínimo, não poderia ser feita desconsiderando elementos preponderantes da realidade, por vezes bastante diversa, das escolas estaduais.

Parece claro que, quando busca a homogeneização, a Secretaria de Estado de Educação desrespeita a diversidade que sabe existir entre as diferentes comunidades escolares. Os alunos chegam aos bancos do segundo segmento do ensino fundamental com bagagens de conhecimento e de habilidades linguísticas muito diversas de uma comunidade para outra, além de as dificuldades apresentadas por cada escola também serem diferentes. Deste modo, exigir que se cumpra o currículo mínimo a qualquer custo, ignorando as necessidades do educando, é, na verdade, um grande desrespeito ao aluno e uma verdadeira desconsideração com seu processo de aquisição de ensino-aprendizagem.

Com isso, o que a iniciativa do Governo do Estado do Rio de Janeiro acaba fazendo é criar dois grupos de professores insatisfeitos: o grupo que tenta cumprir o Currículo Mínimo a todo custo e não tem sucesso, pois seu aluno não acompanha a velocidade do mesmo e, com isso, sente-se frustrado e não recompensado por seu esforço; e o grupo que, consciente das necessidades de seus alunos, reconhece a impossibilidade de seguir o Currículo e, assim, trabalha ciente da desvalorização social, e consequentemente econômica, de seu papel de "não conseguir provar a qualidade de seu ensino".

E o que é ainda pior do que todo esse desgaste causado ao professor é a consequência dele para o aluno: o baixo desempenho nas provas do exame único - o SAERJ - também gera, com frequência, alunos frustrados, desmotivados e com bai$x a$ autoestima. $O$ que a realidade vivida nas escolas em que atuamos com o PIBID aponta, então, é que a busca por uma melhoria na educação vai além da preocupação do cumprimento de um currículo mínimo. Mesmo se tratando de uma amostragem pontual, acreditamos, até pelos alardeados baixos índices de desempenho dos estudantes da rede em exames nacionais, que esta observação seja válida para parte significativa das escolas da rede. Em outras palavras, cremos que a reflexão que pudemos fazer a partir de nosso trabalho seja válida para além de nossos locais específicos de trabalho e ação docente.

Essa discussão em torno da implantação dos Currículos Mínimos serve para contextualizar também nossas possibilidades e limites na formação docente. Afinal, às questões gerais do debate teórico e crítico se associam muitas outras que hoje cercam os profissionais da educação na rede pública estadual (na qual se implementou 0 PIBID/UFF na área de Letras). Agregam-se, assim, ao conjunto de desafios postos para estudantes de licenciatura no que diz respeito às opções didáticas, teóricas e metodológicas, outros tantos, relativos à sobrevivência mesmo de um ensino de qualidade nas escolas públicas, em meio às mais diversas formas de sucateamento constatadas no cotidiano escolar e a um cenário que, em alguns aspectos, não se restringe ao estado, nem mesmo ao país.

Em um mundo no qual tudo se naturaliza como mercadoria e em que as práticas gerenciais de produtividade e controle se anunciam como "naturais" ao ambiente educacional, não falta quem, na academia e em espaços mais declaradamente políticos 
e-Mosaicos - Revista Multidisciplinar de Ensino, Pesquisa, Extensão e Cultura do Instituto de Aplicação Fernando Rodrigues da Silveira (CAp-UERJ)

ANO 1 - V. 1 - N. 2 - DEZEMBRO 2012 - ISSN: 2316-9303

(como sindicatos, associações etc), se proponha a refletir sobre essa relativamente nova situação histórica. Do ponto de vista dos professores, por exemplo, António Nóvoa, educador português, professor catedrático da Universidade de Lisboa e estudioso da profissão docente, caracteriza a contradição que cerca o que ele identifica como o "regresso dos professores" ao centro do debate educacional:

Estamos a assistir, nos últimos anos, a um regresso dos professores à ribalta, depois de quase quarenta anos de relativa invisibilidade. É certo que a sua importância nunca esteve em causa, mas os olhares viraram-se para outros problemas e preocupações: nos anos 70, foi o tempo da racionalização do ensino, da pedagogia por objectivos, do esforço para prever, planificar, controlar; depois, nos anos 80, assistimos a grandes reformas educativas, centradas na estrutura dos sistemas escolares e, muito particularmente, na engenharia do currículo; nos anos 90, dedicou-se uma atenção especial às organizações escolares, ao seu funcionamento, administração e gestão. [...]

Os professores reaparecem, neste início do século XXI, como elementos insubstituíveis não só na promoção da aprendizagem, mas também no desenvolvimento de processos de integração que respondam aos desafios da diversidade e de métodos apropriados de utilização das novas tecnologias.

É este o pano de fundo da minha intervenção: o regresso dos professores ao centro das nossas preocupações e das nossas políticas. [...]

É importante perceber um paradoxo que está na origem de contradições importantes na história da profissão docente: a inflação retórica sobre a missão dos professores implica darIhes uma maior visibilidade social, o que reforça o seu prestígio, mas provoca também controles estatais e científicos mais apertados, conduzindo assim a uma desvalorização das suas competências próprias e da sua autonomia profissional.

Esta realidade está na origem da má notícia que tenho para partilhar convosco: o excesso dos discursos esconde uma grande pobreza das práticas. Dito de outro modo: temos um discurso coerente, em muitos aspectos consensual, estamos de acordo quanto ao que é preciso fazer, mas raramente temos conseguido fazer aquilo que dizemos que é preciso fazer. (NÓVOA, 2007, p.23)

A experiência de formação docente no âmbito do PIBID, portanto, se desenvolve nesse contexto, feito de avanços e limites, de acertos e de equívocos, de esperança e de crítica.

\section{Elementos de balanço: PIBID, EducaÇÃo BÁSICA E FORMAÇÃO DOCENTE}

Em primeiro lugar, é preciso reconhecer que, quando a CAPES torna o supervisor, professor da escola pública onde se implanta o PIBID, também um bolsista do programa, está dado um passo adiante da tradicional relação entre a Universidade e as escolas, via de regra marcada pela desigualdade e pela expectativa de participação voluntária e gratuita dos que atuam na educação básica, para além dos limites dos campi. Parece consenso, entre os educadores da rede que participam do Programa, que a criação do professor supervisor foi um avanço nesta relação, ao tentar romper com o distanciamento entre a teoria universitária 
e-Mosaicos - Revista Multidisciplinar de Ensino, Pesquisa, Extensão e Cultura do Instituto de Aplicação Fernando Rodrigues da Silveira (CAp-UERJ)

ANO 1 - V. 1 - N. 2 - DEZEMBRO 2012 - ISSN: 2316-9303

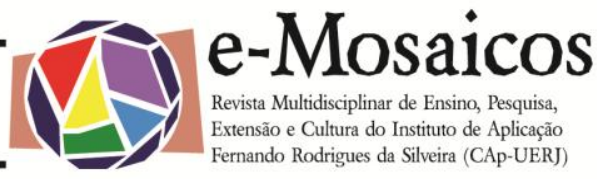

e a prática docente na escola, entendendo este supervisor como co-formador dos licenciandos e reconhecendo formalmente tal relação por meio da concessão de bolsas.

Longe de um treinamento em serviço, o testemunho dos bolsistas participantes do programa é de que eles têm buscado um diálogo permanente com a realidade da escola pública, pela troca de conhecimentos e experiências. Os licenciandos com suas novas ideias, propostas inovadoras de atividades, teorias recentes, e os professores supervisores com a experiência e a prática da sala de aula. Dessa síntese, produziram-se tanto subprojetos atentos às necessidades e interesses reais dos estudantes das turmas em que atuam os licenciandos, quanto uma mobilização das supervisoras no sentido de buscar novos conhecimentos, para tentar superar também alguns dos limites à sua prática docente.

Nessa troca, segundo ainda relatos do grupo de bolsistas em seminário conjunto e nas inúmeras reuniões e discussões, todos saíram mais enriquecidos: os licenciandos, diante não apenas da descrição da realidade escolar contida em livros, mas a efetivamente presenciada por elas, refletem sobre o processo de ensino-aprendizagem e atuam na sala de aula na produção e aplicação de novos materiais; as supervisoras conquistaram um novo espaço de discussão de textos atuais sobre ensino de língua e formação docente. Ainda nessa dinâmica da coformação partilhada pela escola e pela Universidade, os alunos das escolas desfrutaram de aulas mais interessantes e produtivas, enquanto os licenciandos puderam não só constatar que a escola tem vida própria e necessita ser compreendida, como também tiveram a oportunidade de oferecer a ela uma contribuição legítima e necessária para a sua efetiva melhoria.

Prova disso tem sido o empenho do conjunto dos bolsistas em levar para as salas de aula diferentes gêneros textuais (tirinhas, charges, músicas, clipes, poemas, crônicas jornalísticas, crônicas literárias, contos, propagandas, filmes, cartas), a partir de diversas mídias (livros, revistas, jornais, internet, televisão, vídeos), práticas que têm motivado os alunos e muito colaborado com o trabalho docente. As atividades complementam os conteúdos trabalhados, sempre objetivando o exercício das competências relacionadas à codificação e à decodificação de textos nas modalidades oral e escrita para a formação de um cidadão que faz uso consciente e criativo da sua língua materna.

Criou-se, assim, um espaço de crescimento intelectual e profissional no exercício da função do educador real, que está nas escolas, e, para os licenciandos, desenvolvem-se a sensibilidade e a qualificação necessárias à tentativa de contribuir para a superação de dificuldades. Especialmente no desenvolvimento das competências relacionadas à leitura e à escrita nas escolas, é consenso entre nós, professoras formadoras da área de Letras, a avaliação de que os bolsistas-licenciandos têm mostrado mais segurança no contato com os estudantes, maior senso de organização, maior desenvoltura em relação ao novo e inesperado que surge na sala de aula, e principalmente o entendimento de que o professor é um facilitador do processo constante de formação do cidadão, e a consciência de que ser professor é preparar o estudante para utilizar os conhecimentos adquiridos na escola em seu favor na vida diária, isto é, ser professor é formar cidadãos ativos para a vida em sociedade.

O exercício da co-formação, em parceria institucionalmente reconhecida pelo programa de bolsas também para os supervisores, permite um investimento extremamente produtivo nos saberes e nas potencialidades 
e-Mosaicos - Revista Multidisciplinar de Ensino, Pesquisa, Extensão e Cultura do Instituto de Aplicação Fernando Rodrigues da Silveira (CAp-UERJ) ANO 1 - V. 1 - N. 2 - DEZEMBRO 2012 - ISSN: 2316-9303

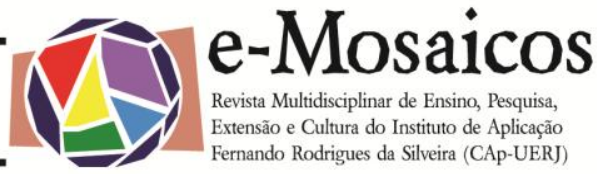

dos professores das escolas públicas. Desse sentido de construção coletiva resulta tanto uma inserção mais qualificada dos licenciandos nas escolas, quanto um incentivo para que os próprios supervisores se engajem em atividades formadoras, tais como discussão de textos teóricos, reflexão sobre documentos oficiais, sejam os de abrangência nacional (PCN, OCN), sejam aqueles estabelecidos pelo Estado do Rio de Janeiro (Currículos Mínimos).

Para os licenciandos, trata-se de oportunidade importante de inserção na prática docente, superando os lugares-comuns que cercam, por um lado, o exercício da docência na educação básica, e, por outro, o sentimento de quase obrigatoriedade de seguir carreira acadêmica e buscar apenas o exercício do magistério em nível superior. Especificamente na área de língua portuguesa, o contato com o fenômeno da variabilidade linguística, sem a legitimação do preconceito, tem se mostrado um campo importante de descobertas e reflexões para os estudantes de Letras. Assim, as atividades desenvolvidas pelo Programa parecem, de fato, contribuir, ainda que no microcosmo das escolas e turmas em que atuamos, para a superação de um imaginário que cristalizou as aulas de português como momentos de repetição e memorização de modelos de análise construídos a partir de enunciados irreais e fragmentários.

A maior contribuição que o PIBID pode trazer para as licenciaturas talvez seja pautar, como demanda contínua, o diálogo entre os saberes acadêmicos e o exercício do magistério. Não se trata de uma adequação rasa dos conteúdos universitários ao universo escolar, mas da reflexão de como estes podem contribuir para a construção de uma autonomia intelectual e pedagógica, na contramão do processo de fetichização, de desligamento entre produção acadêmica e reprodução escolar de saberes. 0 sucesso em tal tarefa não pode ser mensurado em curto prazo, mas sua busca constitui, sem dúvida, um horizonte importante.

\section{REFERÊNCIAS BIBLIOGRÁFICAS:}

AZEREDO, José Carlos de. Ensino de português: fundamentos, percursos, objetos. Rio de Janeiro: Jorge Zahar Ed., 2007.

BRAIT, Beth. PCNs, gêneros e ensino de língua: faces discursivas da textualidade. In: ROJO, Roxane (org.). A prática de linguagem em sala de aula. Praticando os PCNs. Campinas, São Paulo: Mercado das Letras, 2000.

BRASIL. Coordenação de Aperfeiçoamento de Pessoal de Nível Superior (CAPES). PIBID - Programa Institucional de Bolsa de Iniciação à Docência. Disponível em http://capes.gov.br/educacao-basica/capes pibid

BRASIL, Secretaria da Educação Fundamental - Parâmetros Curriculares Nacionais: Língua Portuguesa. Brasília: MEC/SEF, 1997.

NÓVOA, Antonio. "O regresso dos professores". Comunicações da Conferência para o desenvolvimento profissional de professores para a qualidade e para a equidade da aprendizagem ao longo da vida. Lisboa, 27 e 28 de Setembro de 2007.

PETIT, Michele. Os jovens e a leitura: uma nova perspectiva. Trad. Celina Olga de Souza. São Paulo: Ed. 34, 2008.

RIO DE JANEIRO. Secretaria de Estado de Educação. Currículos mínimos. Disponíveis em http://www.rj.gov.br/web/seeduc. 
${ }^{1}$ Diretora adjunta do Colégio Estadual Raul Vidal, em Niterói (RJ), e professora de Língua Portuguesa da rede municipal de São Gonçalo (RJ); supervisora do PIBID - UFF.

2 Professora adjunta de Pesquisa e Prática de Ensino da Universidade Federal Fluminense e do Instituto de Aplicação da UERJ; coordenadora da área de Língua Portuguesa do PIBID- UFF.

3 Professora de Língua Portuguesa do Colégio Estadual Joaquim Távora, em Niterói (RJ); supervisora do PIBID-UFF. 